\title{
Thermal Resistance of Graphite Plastics Based on Aromatic Polyamide
}

\author{
Aleksandr Burya, Yekaterina Yeriomina, Olga Naberezhnaya, Nina Arlamova \\ Dniprovsk State Technical University, Kam'yanske, Ukraine \\ Email: ol.burya@gmail.com
}

How to cite this paper: Burya, A., Yeriomina, Y., Naberezhnaya, O. and Arlamova, N. (2018) Thermal Resistance of Graphite Plastics Based on Aromatic Polyamide. American Journal of Analytical Chemistry, 9, 331-339.

https://doi.org/10.4236/ajac.2018.97026

Received: March 30, 2018

Accepted: July 13, 2018

Published: July 16, 2018

Copyright $\odot 2018$ by authors and Scientific Research Publishing Inc. This work is licensed under the Creative Commons Attribution International License (CC BY 4.0).

http://creativecommons.org/licenses/by/4.0/

\begin{abstract}
The paper presents the results of studying graphite plastics based on heat-resistant polyamide by thermogravimetric analysis (TGA), as well as the determination of mechanisms and kinetic parameters by the Koats-Redfern method. Based on the results of the thermal analysis, the mechanisms and kinetic parameters of the thermal destruction process were determined, namely: graphite injection increases the heat resistance of graphite plastics by 2 (graphite content $10 \%$ by weight) - $22 \%$ (graphite content $50 \%$ by weight) and reduces the activation energy of the process thermal destruction almost 2 times. This makes it possible to improve the technological parameters for the production of polymeric composite materials, which are limited by a narrow interval between the flow temperatures and the thermal destruction of phenylone $\mathrm{C}-2$.
\end{abstract}

\section{Keywords}

Graphite Plastics, Thermal Resistance, Kinetic Parameters

\section{Introduction}

Thermoplastics are widely used in all industries because of their complex properties. They are used in the manufacture of parts of electrical appliances and wireless kits, friction units, seals and parts that work in chemically active environments [1]. Thermoplastics have already reached their tensile strength, their limit of thermal and wear resistance in certain extent. And the development of technology sets the task of further improvement of the properties of materials in combination of efficiency in aggressive substances and reducing the product itself [2]. The task of increasing the operating characteristics is solved by polymer composites. Graphite plastics are interesting representatives of such materials. 
They are composition materials based on carbon-graphite fillers and polymer binders. Carbon-graphite fillers are characterized by high reagent and heat resistance, low density $\left(1.22-2.25 \mathrm{~g} / \mathrm{cm}^{3}\right)$ and porosity $(20 \%-30 \%)$, developed surface of particles [1] [3].

When using thermoplastic binders with a low degree of filling, materials with elevated resistance toward shock loads and low thermal coefficient of linear expansion [up to $(3-10) \times 10^{-5}{ }^{\circ} \mathrm{C}^{-1}$ ], reduced coefficient of thermal conduction [up to $0.7-1.0 \mathrm{~W} /(\mathrm{m} \cdot \mathrm{K})$ ] are obtained. Graphite plastics of such type can be used for manufacturing of the structural details of complex shape [4].

All kinds of graphite plastics are prone to self-lubrication (coefficient of friction $0.05-0.20$ ), the intensity of their wear is $10^{-9}-10^{-12} \mathrm{~mm} / \mathrm{m}$ depending on the operating conditions. Units of friction which are made of graphite plastics withstand several times higher shock loads and normal static loads in comparison with antifriction graphite materials. They also can be exploited in the conditions of half-liquid friction, however maximum service temperature of graphite plastics is 1.5 - 3 times lower than the required parameters (usually it is determined by the thermal resistance of binder) [3], which leads to premature failure of the part.

Thus, the aim of the work was to study the thermal destruction of aromatic polyamide and graphite plastic based on it, as well as the kinetic parameters of the process of thermal degradation by the Koats-Redfern method.

\section{Materials and Methods of Research}

The heat-treated samples of aromatic polyamide phenylone C-2 (TU 6-05-221-101-71) and graphite plastics on its base with the content of graphite 10 - $60 \mathrm{wt} \%$ were subjected to TGA analysis.

The technology of obtaining graphite plastics includes the preparation of raw materials: the dosing and mixing of the original components, subsequent mixing of composition in the rotating electromagnetic field with the participation of ferromagnetic element, formation in the product by compression molding. Molds and pouring gates of equipment had both elevated strength and wear resistance.

Thermal destruction of obtained samples was studied on the derivatographQ-1500D of the system of F. Paulik, J. Paulik and L. Erdey, MOM company (Hungary). The tests were conducted in special ceramic crucibles on air in the temperature interval $298-873 \mathrm{~K}$. The speed of temperature rise- $10 \mathrm{~K} / \mathrm{min}$, $\mathrm{Al}_{2} \mathrm{O}_{3}$ was used like a standard substance (inert), sample weight $-100 \mathrm{mg}$. The sensibility of DTG and DTA was $1 / 5$ and $1 / 3$ respectively.

Mathematically, for a non-isothermal kinetic analysis of the curve obtained with a linear heating, there are two methods: integral and differential ones. In this paper the method of Coates-Redfern [5] [6] was used with applying the integral kinetic equations, which allows for consideration of non-isothermal reaction within the infinitesimal time interval as isothermal one. 


\section{Results and Discussion}

The analysis of the results of DTA-curves of phenylone and graphite plastics on its base showed (Figure 1) that in the interval of temperatures from 273 up to $623 \mathrm{~K}$ we can observe an endothermic area with gradual decrease in mass $(3 \%$ $6 \%$ ) which is accompanied by release of moisture. Thermal destruction of phenylone starts at $723 \mathrm{~K}$ but at the same tame of graphite plastics containing 10 $20 \mathrm{wt} \%$ - at $803 \mathrm{~K}$, and observed at temperature $848 \mathrm{~K}$-from of graphite plastics contain 30 - $60 \mathrm{wt} \%$ of graphite (thermostability increases by 125 degrees, in comparison with the original phenylone). In the temperature range of $673-873$ $\mathrm{K}$ the peaks, which show the decomposition of the material, are observed on both initial phenylone and graphite plastics.

The studying of thermal resistance of initial plastic and graphite plastics on its base (Figure 2) shows that all curves "weight loss-temperature" are similar, and its that the decomposition of graphite plastics proceeds similar to the initial polymer. What is more, the compositions containing $10-20 \mathrm{wt} \%$ of filler almost overlap each other, because the small content of the graphite in the matrix of polymer has little effect on the displacement of TG-curves.

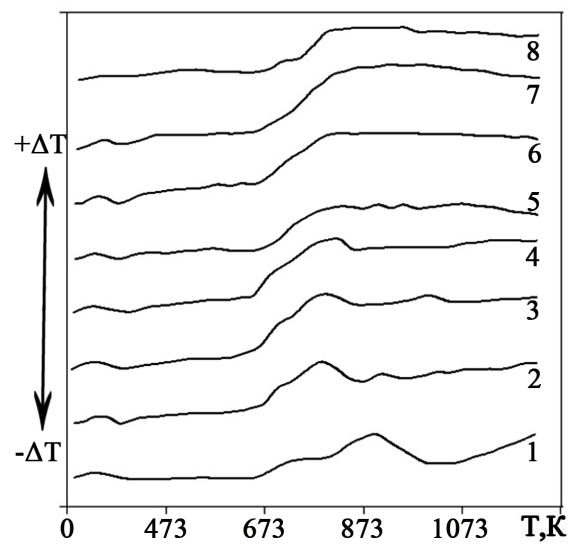

Figure 1. DTA-curves of phenylone (1) and graphite plastics on its base with the content of graphite: 10 (2), 15 (3), 20 (4), 30 (5), 40 (6), 50 (7), 60 (8) wt\%.

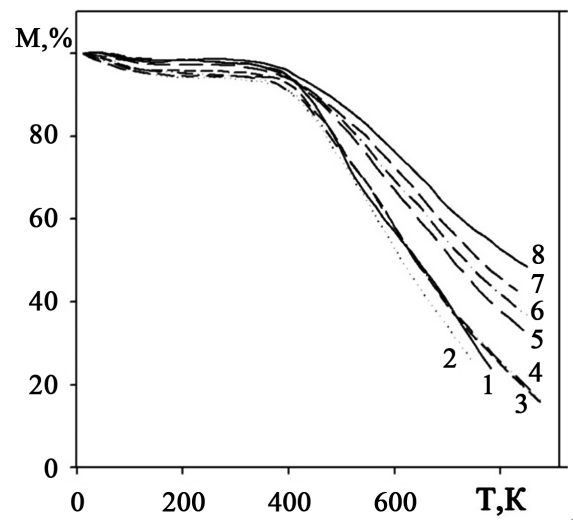

Figure 2. TG-curves of phenylone and graphite plastics on its base with the content of graphite: 10 (2), 15 (3), 20 (4), 30 (5), 40 (6), 50 (7), 60 (8) wt\%. 
The introduction of $30-60 \mathrm{wt} \%$ of graphite in polymer matrix increases thermal resistance graphitplastics in comparison with phenylone on $2 \%-22 \%$ (Figure 2, Table 1). Most likely, an increase of thermal indicators evidences the processes of structuring and intensity of the mechanisms of the interaction between phenylone and filler, i.e., the crosslinking of macromolecules of phenylone between themselves and with the particles of graphite.

In order to select the optimal kinetic model to describe the thermal destruction of materials from the experimental data obtained by TG-analysis, we considered the possibility of using mathematical models of various heterogeneous processes [5] [6].

The difficulties in assessing the kinetic parameters of the processes of the solids' thermal decomposition at a predetermined temperature range are known to be associated with a large number of conflicting data that has been obtained on the basis of kinetic equations describing various solid phase conversions. However, the references consideration allows [6] [7] to state that there is a stereotype describing solid-phase processes with a selection of chemical-process conversion $\alpha$ as a criterion which is determined by the formula [7]:

$$
\mu=\left(m_{o}-m\right) /\left(m_{o}-m_{1}\right)
$$

where $m_{o}, m, m_{1}$ is initial, current and final mass of the sample.

The time dependence of the degree of conversion can be expressed by means of a differential equation [6]:

$$
\mathrm{d} \mu / \mathrm{d} \tau=k f(\mu)
$$

where $\tau$ is time; $k$ is the constant value of the reaction speed; $f(\mu)$ is the algebraic function describing the mechanism of the process.

The dependency $k$ on the temperature is described by means of a widely known Arrhenius equation [7]:

$$
k=Z \mathrm{e}^{-E_{a k t} / R T}
$$

Table 1. Thermal resistance of phenylone and graphite plastics on its base with different content of the filler.

\begin{tabular}{cccccc}
\hline Graphite content, wt. \% & $T_{10}$ & $T_{20}$ & $T_{30}$ & $T_{40}$ & $T_{\text {Vmax }}$ \\
\hline 0 & 699 & 757 & 802 & 853 & 689 \\
10 & 703 & 773 & 833 & 885 & 702 \\
15 & 708 & 778 & 842 & 901 & 708 \\
20 & 711 & 784 & 851 & 913 & 699 \\
30 & 718 & 803 & 883 & 953 & 695 \\
40 & 743 & 836 & 922 & 1003 & 704 \\
50 & 753 & 856 & 941 & 1034 & 703 \\
\hline
\end{tabular}

Note: $T_{10}, T_{20}, T_{30}, T_{40}$-temperatures, K; $10 \%, 20 \%, 30 \%$, $40 \%$ weight loss. 
where $R$ is a universal gas constant, $\mathrm{kJ} / \mathrm{kg} \cdot \mathrm{K} ; T$ is the temperature, $\mathrm{K} ; e$ is the base of a natural $\operatorname{logarithm} ; Z$ is a pre-exponential factor; $E_{a k t}$ is the apparent activation energy, $\mathrm{kJ} / \mathrm{mole}$.

Given the dependence (2), the Equation (1) was presented as follows:

$$
\mathrm{d} \mu / \mathrm{d} \tau=Z \mathrm{e}^{-E_{a k t} / R T} f(\mu)
$$

Mathematically, for a non-isothermal kinetic analysis of the curve obtained with a linear heating, there are two methods: integral and differential ones. In this paper the method of Koates-Redfern [6] was used with applying the integral kinetic equations, which allows for consideration of non-isothermal reaction within the infinitesimal time interval as isothermal one. After integration and using the logarithms, the dependence (3) looks as follows:

$$
\lg \frac{k^{\prime}(\mu)}{T^{2}}=\lg \frac{Z R}{\frac{\mathrm{d} T}{\mathrm{~d} \tau} \cdot E_{a k t}}\left(1-\frac{2 R T}{E_{a k t}}\right)-\left(\frac{E_{a k t}}{2.3 R T}\right),
$$

where $k^{\prime}(\mu)=\int_{0}^{\mu} \frac{\mathrm{d} \mu}{f(\mu)} ; k^{\prime}(\mu)=\frac{(1-\mu)^{1-n_{p}}-1}{n_{p}-1}$ at $n_{p} \neq 1 ; k^{\prime}(\mu)=-\ln (1-\mu)$; at $n_{p}=1$, where $n_{p}$-order of reaction.

Assuming that the relationship $\left[\lg k^{\prime}(\mu)\right]-[1 / T]$ is linear [3], in which case it can be used to determine the mechanism of heterogeneous reactions. This dependence is calculated directly from the experimental values $\mu$ and $T$ is linear only for such a function $k^{\prime}(\mu)$, which corresponds to the most probable processes controlling the actual speed of the reaction [7].

Determine the possible mechanism and calculation of the kinetic parameters of thermal destruction of the substances under study was carried out using the integral kinetic equations of different mechanisms of heterogeneous processes [7]. The criteria for selection of the mathematical simulation were direct correlation coefficient $(r)$ within the coordinates of the Arrhenius equation and the minimum of function $(S)$ :

$$
\begin{gathered}
S=f\left\{\mu(\tau), T(\tau), \Delta T(\tau), E_{a k t}, Z\right\}, \\
S=\sqrt{\frac{\sum\left(\mu_{e}-\mu_{p}\right)^{2}}{m_{e}}}
\end{gathered}
$$

where $\mu_{e}, \mu_{p}$ are experimental and calculated values of the degree of conversion; $m_{e}$ is the number of experimental data.

Calculation results of the kinetic parameters of thermal destruction of the substances under study were all calculated by the program [7] [8] developed for IBM and cited in Table 2.

The analysis of thermal destruction of initial phenylone C-2 showed that the correlations, which are derived from the following mathematical models, are closest to a unit value of the coefficient:

$$
k \tau=3\left[1-(1-\mu)^{1 / 3}\right]
$$


Table 2. Calculation results of the kinetic parameters of thermal destruction of phenylone $\mathrm{C}-2$ and composites on its base.

\begin{tabular}{|c|c|c|c|c|}
\hline Mathematical model of the process & $r$ & $S$ & $E_{a k t}, \mathrm{~kJ} / \mathrm{mole}$ & $\lg Z$ \\
\hline 1 & 2 & 3 & 4 & 5 \\
\hline \multicolumn{5}{|c|}{ Phenylone C-2 } \\
\hline (4) & 0.986 & 0.028 & 129.99 & 3.41 \\
\hline (5) & 0.978 & 0.036 & 153.73 & 4.75 \\
\hline (6) & 0.995 & 0.015 & 202.62 & 6.58 \\
\hline (7) & 0.993 & 0.055 & 235.61 & 8.47 \\
\hline (8) & 0.988 & 0.309 & 279.05 & 10.46 \\
\hline \multicolumn{5}{|c|}{ Phenylone C-2 + 10 Graphite, wt\% } \\
\hline$(4)$ & 0.995 & 0.016 & 108.13 & 2.18 \\
\hline$(5)$ & 0.991 & 0.022 & 126.56 & 3.23 \\
\hline (6) & 0.998 & 0.011 & 174.07 & 4.99 \\
\hline (7) & 0.998 & 0.044 & 201.05 & 6.53 \\
\hline (8) & 0.996 & 0.311 & 235.32 & 8.01 \\
\hline \multicolumn{5}{|c|}{ Phenylone C-2 + 15 Graphite, wt $\%$} \\
\hline (4) & 0.997 & 0.015 & 116.20 & 2.61 \\
\hline$(5)$ & 0.991 & 0.023 & 158.11 & 3.85 \\
\hline (6) & 0.999 & 0.012 & 181.15 & 5.35 \\
\hline$(7)$ & 1.000 & 0.044 & 211.49 & 7.07 \\
\hline (8) & 0.997 & 0.308 & 251.55 & 8.86 \\
\hline \multicolumn{5}{|c|}{ Phenylone C-2 + 20 Graphite, wt $\%$} \\
\hline$(4)$ & 0.986 & 0.023 & 80.35 & 0.74 \\
\hline (5) & 0.981 & 0.027 & 90.83 & 1.36 \\
\hline (6) & 0.996 & 0.013 & 143.53 & 3.43 \\
\hline (7) & 0.993 & 0.046 & 160.29 & 4.44 \\
\hline$(8)$ & 0.989 & 0.275 & 180.21 & 5.14 \\
\hline \multicolumn{5}{|c|}{ Phenylone C-2 + 30 Graphite, wt $\%$} \\
\hline$(4)$ & 0.989 & 0.023 & 74.53 & 0.27 \\
\hline$(5)$ & 0.985 & 0.029 & 85.37 & 0.90 \\
\hline (6) & 0.996 & 0.011 & 131.22 & 2.50 \\
\hline (7) & 0.994 & 0.051 & 147.95 & 3.48 \\
\hline (8) & 0.992 & 0.272 & 168.37 & 4.19 \\
\hline \multicolumn{5}{|c|}{ Phenylone C-2 + 40 Graphite, wt $\%$} \\
\hline$(4)$ & 0.997 & 0.007 & 63.69 & -0.16 \\
\hline$(5)$ & 0.998 & 0.007 & 76.95 & 0.60 \\
\hline (6) & 0.995 & 0.010 & 102.05 & 1.20 \\
\hline (7) & 0.997 & 0.050 & 121.78 & 2.36 \\
\hline$(8)$ & 0.998 & 0.322 & 146.57 & 3.32 \\
\hline
\end{tabular}




\section{Continued}

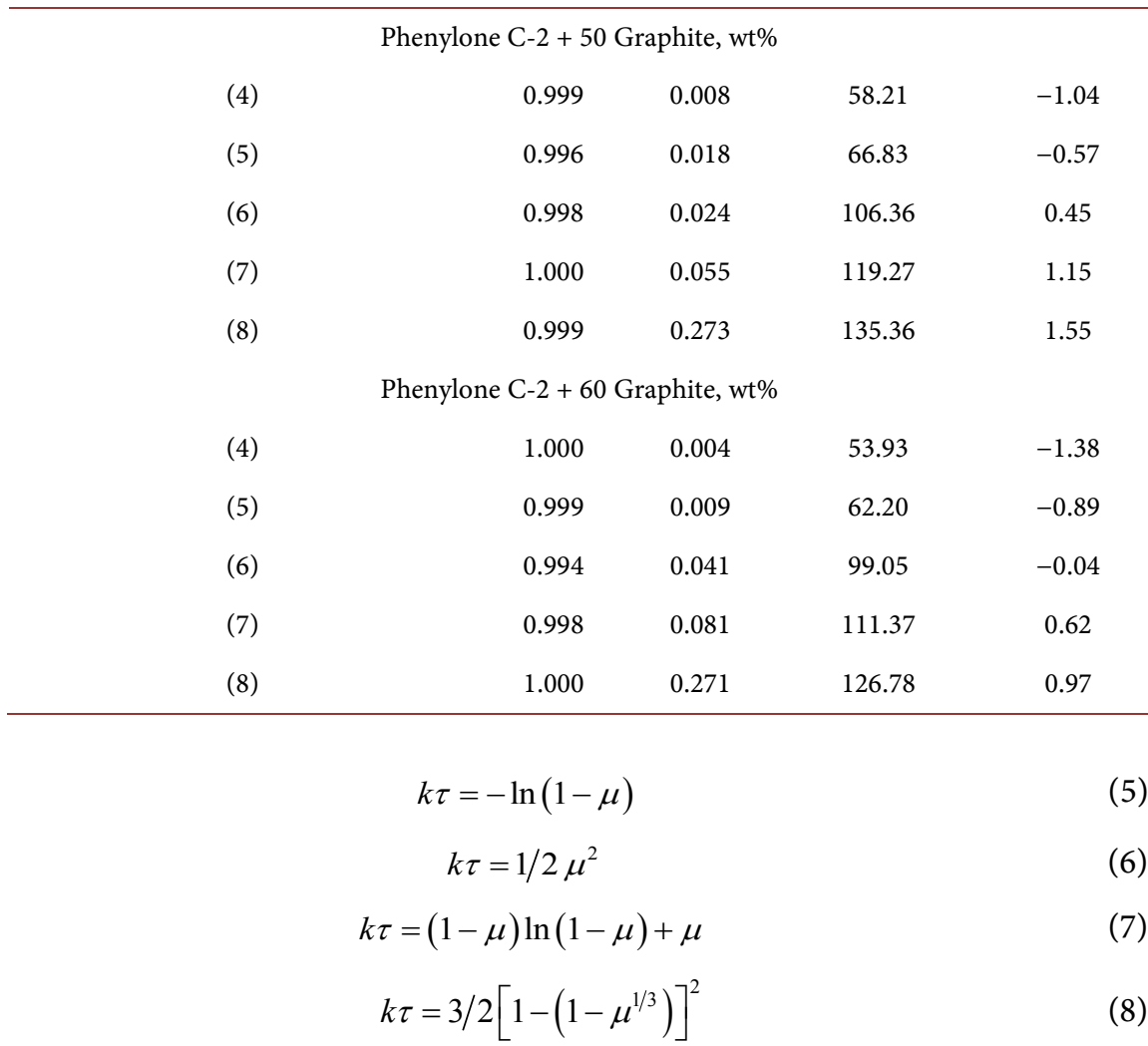

From the results it's obvious that a certain part of reactions of thermal destruction has a radical chain mechanism [5] consisting of the following stages: I-initiation; II-chain development; III-chain transfer; IV-chain break. As it's showed in [7] the origin of the chains is the result of polymer chain break, and free radical is formed. It's easily broken up with the cleavage of the monomer molecule, i.e., by reaction, the reverse reaction of chain growth. A new free radical is formed in the result of the break. It differs from initial only in the length of the chain. It, in its turn, cleaves one more monomer molecule, and the process continues until the polymer macromolecule breaks up completely or until the free valence on the end of the polymer chain disappears in the result of transfer reaction or chain break.

As it is known [9], during the thermal destruction of polymers containing aromatic rings in the chain, the main stage is that of chain initiation. This was confirmed by calculation, as the kinetic equation of the first order (5) describes the process of random nucleation: phenylone undergoes monomolecular conversion, which result in the formation of valence-saturated molecules' radicals possessing a relatively low reactivity. Given that the thermolysis of phenylone primarily leads to the cleavage of the weakest $\mathrm{Ph}-\mathrm{N}$ and $\mathrm{C}-\mathrm{N}$ links [9], it can be assumed that the model (5) describes the below-mentioned homolytic process with the formation of free radicals (Figure 3).

Another way to adequately reflect the process is the mathematical model of the reactions at the interface (4). Obviously, the chain development occurs here 


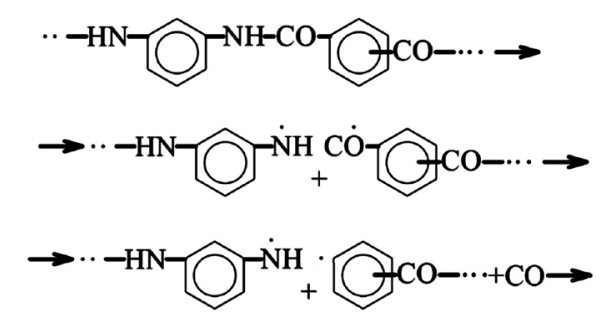

Figure 3. Homolytic process of the thermolysis of ohenylone with the formation of free radicals.

as a result of heterogeneous reactions at the interface "polymer-gaseous thermolysis products" $\left(\mathrm{CO}_{2}, \mathrm{CO}, \mathrm{H}_{2}, \mathrm{H}_{2} \mathrm{O}, \mathrm{NH}_{3}\right.$ etc.).

The mathematical models ( 6 - 8) represent one-, two- and three-dimensional diffusion of particles in the polymer matrix-the particles diffuse to the ash layer which accumulates as the phenylone burns out. Obviously, this process is slower because it requires more energy for activation (see Table 2).

Similarly, the kinetic parameters ofgraphite plastics based on phenylone (Table 2) were calculated. As expected, the same mathematical model as in the case of the initial phenylone can adequately describe thermal destruction of graphite plastics. Based on the results it was found that the introduction of $60 \%$ of graphite leads to the decrease of activation energy of thermal destruction process almost in times.

\section{Conclusion}

By the results of thermal analysis we determined the mechanisms and kinetic parameters of the thermal destruction process of the studied materials using Koats-Redfern method. The studying of thermal resistance of initial plastic and graphite plastics on its base (Figure 2) shows that all curves "weight loss-temperature" are similar. It is found that the introduction of graphite (30 - $60 \mathrm{wt} \%)$ increases thermal resistance graphit plastics on $2 \%-22 \%$ and decreases activation energy of thermal destruction process almost 2 times. It is established that a certain part of the thermal destruction reactions has a radical chain mechanism with using the mathematical models of various heterogeneous processes by the Koats-Redfern method. It makes it possible to improve the technological parameters of the production of polymer composite materials which are limited to a narrow interval between flow temperatures and thermal destruction of phenylone $\mathrm{C}-2$.

\section{References}

[1] Kargina, V.A. (1972) Entsiklopediya polimerov, Vol. 1. 1224.

[2] Stolyarova, V.A., Shegel', F.I. and Mamatov, Yu.M. (1980) Vliyaniye agressivnoy sredy na svoystva antifriktsionnykh materialov. Plasticheskiye massy, No. 1, 20-22.

[3] Lazarev, G.E., Kharlamova, T.L. and Vereykin, V.I. (1981) Osobennosti treniya i iznashivaniya materialov v agressivnykh sredakh. Treniye i iznos, 2, 43-52.

[4] Lapteva, V.G., Dokuchayeva, Ye.N. and Kaplina, V.F. (1987) Iznosostoykost' par 
treniya tekhnologicheskogo oborudovaniya pri ispol'zovanii tribopolimerobrazuyushchikh smazochnykh materialov. Treniye i iznos, 6, 98-106.

[5] Shestak, Y.A. (1987) Teoriya termicheskogo analiza: Per. s angl. M.: Mir, 455 p.

[6] Zuru, A.A., Uaytkhed, R. and Kriffits, D.L. (1990) Novaya metodika opredeleniya vozmozhnogo mekhanizma reaktsii iz neizotermicheskikh termogravimetricheskikh dannykh. Termokhim. Acta, 285-305.

https://doi.org/10.1016/0040-6031(90)80445-5

[7] Emanuel', N.M. and Knorre, D.G. (1969) Kurs khimicheskoy kinetiki. M.: Vysshaya shkola. 432 p.

[8] Burya, A.I., Arlamova, N.T., Kholodilov, O.V. and Sytnik, S.V. (2001) Issledovaniye termodestruktsii fenilona i ugleplastikov na osnove fenilona. Materialy. Tekhnologii. Instrumenty, 6, 58-61.

[9] Korshak, V.V. (1970) Khimicheskoye stroyeniye i temperaturnyye kharakteristiki polimerov. M.: Nauka, 420 p. 